'TECHNICAL ASSESSMENT OF THE POTENTIALS OF PULSED HIGH-BETA PLASMA DEVICES AS CTR RADIATION TEST FACILITIES

BY

P. J. Persiani

- Notice- iccoun of woik

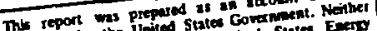

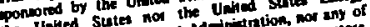

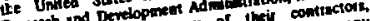

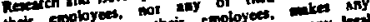

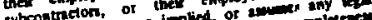

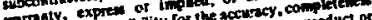

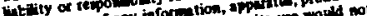

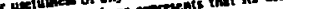

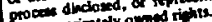

propin princtely owned riphes.

FOR PRESENTATION AT

3rd Topical Conference on Pulsed High Beta Plasmas

UKAEA CULHAM LABORATORY

Abingdon, Oxon, England

September 9-12, 1975

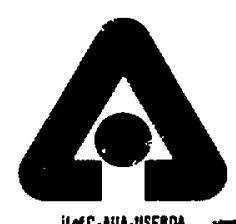




\title{
TECHNICAL ASSESSMENT OF THE POTENTIALS \\ OF PULSED HIGH-BETA PLASMA DEVICES AS CTR RADIATION TEST FACILITIES*
}

\author{
P. J. Pergiani \\ Argonne National Laboratory \\ Argonne, Illinois 60439, U.S.A.
}

\section{INTRODUCTION}

Major radiation test facilities will be necessary in the near-term (five years) and long-term ( $>10$ years) future for the timely development and understanding of fusion confinement systems and of prototype fusion power reactors. The study includes the technical justifications and requirements for CTR Neutron and Plasma Radiation Test Facilities. In assessing the technical justification and requirements for a CTR Radiation (plasma and neutron) Test Facility, it is necessary to delineate the CTR Materials Program into two general areas of study: surface radiation effects and bulk radiation effects.

1. Surface Radiation Effects. The surface radiation effects involve the study of the primary and secondary plasma radiation (MeV neutrons, energetic particles and ions, $x$ rays, bremsstrahlung, soft $x$ rays, and synchrotron radiation) interaction effects on the immediately adjacent wall materials. The resulting blistering, sputtering, and particle emission lead to wall erosion and plasma contamination, which in turn influences the physics of plasme confinement and heating. A most important aspect of the overall surface area problem is that the incident radiation field is a spectrum of reaction mechanisms. The surface problem relates directly to the plasma physics and confinement experi ments currently being carried out in the major CTR laboratories.

2. Bulk Radiation Effects. The bulk radiation effects involve the study of fusion spectra (eV to $14 \mathrm{MeV}$ ) neutrons with the structural component materials of high-powered fusion reactors. The volume integrated (bulk) neutron fluence effects on the physical and mechanical properties, creep strength, ductility, and dimensional instability (swelling) relate to the design problems of the more long-range development of prototype and/or demoustration fusion power reactors. However, the high-performance conditions associated with the power reactors necessitate the early study of materials under intense neutron radiation conditions.

\section{PLASMA SOURCE}

The recent advances made in surface physics by the investigators at several laboratories have placed a timely priority in this area of study. The planned experinental program has been extended to study surface effects which require diverse radiation sources and at intensity levels higher than those currently available. The minimum neutron fluence needed to obtain observable measurements for surface effects is approximately $10^{17}$ to $10^{18} \mathrm{n} / \mathrm{cm}^{2}$. The program emphasizes the need for studying the simultaneous impact of radiation on surface materials. This exphasis is consistent with the increasing preoccupation of the plasma physicists in the confinement program on the effects of wall impurities and plasma contamination in the present generation of plasma physics experiments [1-11]

The test conditions for the bulk radiation. studies require neutron fluxes and f.luences of one or two orders of magnitude greater than the needs specified in the surface science program. The minimum neutron fluence requirements for measuring: observable bulk effects are greater than $10^{20}$ to $10^{21} \mathrm{n} / \mathrm{cm}^{2}$. Neutron source facilities in the energy range and intensities of long-term interest to the CTR program are presently not available. However, there are some basic materials studies

*Work perforned under the auspices of the U.S. Energy Research and Development Administration. 
(neutron and ion-bombardment correlation experiments, void formation, defect formation, etc.) which may be satisfied with the neutron flur levels in the upper range required by the surface program.

An important asfect of a thermal plasma device is that the simultaneous yield of neutrons, energetic particles, bremsstrahlung, soft $x$ rays, and. synchrotron radiation, makes possible the study of the synergistic effects of the radiation fields on the vacuum-wall materials. The total plasma radiation environment may more closely simulate the integral effects anticipated at the first wall of a fusion device or reactor, but at lower intensity. The simulacion results from the fact that in thermonuclear plasma reactions the relative intensity ratios of the neutrons and alpha particles, and the bremsstrahlung. radiation, are constant and independent of the type of confinement device. The intensities are each proportional to the square of the ion density. The relative ratio with respect to the synchrotron radiation is inversely proportional to $\beta$ (the ratio of plasma to magnetic field pressure) and as such is apparently device dependent. However, the extent of this dependency will rely on the opacity of the plasma to this radiation.

Selective filtering of the separate ra: capability for differential and integral surface effects studies and, in addition, bulk radiation effects for neutron fluxes of sufficient intensity.

\section{DENSE PLASMA FOCUS (DPF)}

of the many types of currently operable plasma devices, the dense plasma focus [12-16] has been consistently and systematically developed and scaled to yield themonuclear plasmas of deuterium gas with $(D, D)$-neutron source strength thus far achieved at an intensity of $1.2 \times 10^{12} \mathrm{n} / \mathrm{pulse}$ in approximately $1 \mathrm{~cm}^{3}$ volume.

Recent experimental results and analyses consistent with these results have been translated into a generally accepted model describing the characteristic behavior of the plasma [13-16]. In some devices the initial intense]y pinched plasma, formed at the time of collapse, yields a small burst of neutrons with a 40-nsec lifetime. The consequent disruption and turbulent motion enhances the ohmic heating of the plasma and results in yielding the main (second) burst of neutrons with a 100-nsec pulse width. In other designs, only a single burst of neutrons with a 100-nsec pulse width is observed.

At high enough gas filling pressures, the neutron and $x$-ray emissions are predominantly of thermonuclear origin, with the neutron energy spectrum at $2.5 \pm 0.1$ $\mathrm{MeV}$ and an isotropic distribution. A small fraction of the neutrons may result from an acceleration ion beam-target mechanism characterized by energies of approximately 2.8-3.2 MeV and a marked anisotropic distribution along the axis.

Experiments have shown that at high pressures (10 Torr) the focus is a thermalized plasma yielding thermonuclear neutron and $x$-ray radiation. At low pressure conditions ( $<2-3$ Torr) the ion-accelerator mechanism is enhanced until at low enough pressures the acceleration-target mode is the predominant mechanism for the neutron source [13-16]. In this operating regime and depending on the design of the device, there exists a hard $x$-ray component arising from the ionbeam interaction on the electrode face.

The utilization of the dense plasma focus device as a radiation test facility for the CTR program will therefore require that the device be operated in the higt-pressure mode in order to more closely simulate thermonuclear plasma sources.

1. Neutron Scaling. The scaling laws for $(D, D)$ neutrons can be related to the plasma current at the time of maximum compression and heating and, in turn, to the stored capacitor-bank energy. From the general relations between the significant parameters, the neutron yield is expected to increase approximately with the square of the capacitor-bank energy [17]. Deviations from the square law is influenced by the electrical circuitry of the total system, i.e., impedance matching, capacitance, inductance, voltage, and current.

2. DPF Device as a Plasma Source. In order to scope the potential for developing the plasma focus discharge into a plasma radiation test source, the scaling laws adopted for neutron-production estimates have been based on the systematic set of Mathez's systems experiments conducted at LASL [18]. The 
maximum neutron yield reported $i s 1.2 \times 10^{12} \mathrm{n} /$ pulse at the capacitor-bank energy of $420 \mathrm{~kJ}$.

3. Deuterium-Tritium Gas. The neutron production for a 50-50 deuteriumtritium gas mixture from a series of LASL experiments resulted in $(D, T) /(D, D)$ ratios of approximately $80-100$, which are consistent with the expected crosssection ratio for plasma temperatures in the range of $1-10 \mathrm{keV}$. The generally accepted scaling factor for $a(D, T)$ system is taken as approximately 80 .

4. Pulsed-energy Storage and Transfer System. The repetitive pulsing characteristics of a plasma device will be an important consideration in determining the development potential as a radiation test facility. Repetition rates of several pulses per second are necessary to not only establish feasibility but would introduce important options in the scaling program. For plasma focus devices, the total scaling is effected by the capacitor-bank energy and repetition rate. Options will exist to allow high energy at low repetition rates or low energy at high repetition rates for a given total power level. A modest development program to design commercially producible capacitors and swttching systems having a lifetime of $>10^{7}$ cycles would not introduce a time delay in the utilization of some of the proposed pulsed devices.

5. Potential Utility of a DPFRTF. A summary of the potential design parameters for developing the DPF device into a radiation test facility is given in Table I. In scaling the experimental data to facility design parameters, an upper limit of $10 \mathrm{MW}$ was adopted as a reasonable operating power level for a research test facility (e.g., fission research reactors). This power level allow a flexibility in setting the capacitor-bank energy and repetition rate to meet the needs of surface and bulk materials program provided the problems of cooling and lifetime of electrodes are solvable. A $2 M \mathrm{MJ}-60 \mathrm{kV}$ system is a factor of five greater than the operating experience on the LASL $420 \mathrm{~kJ}$ - $46 \mathrm{kV}$ system. This extrapolation will eventually be decreased to factors of three and two as experience is gained from the $1 \mathrm{MJ}-40 \mathrm{kV}$ experiments being planned at the Euratom laboratories (Frascati, Culham, Jülich), Lawrence Livermore Laboratory, and the CEA Limeil Laboratory in France.

The extrapolated neutron source strengti is within the range of $5 \times 10^{15}$ to $1 \times 10^{16} \mathrm{n} / \mathrm{sec}$ for a 5 pps repetition capability. Achieving these operating conditions makes possible much higher flux levels available for experiments depending on the engineering layout design of the facility. A vertical installation allows a complete radial access to the plasma source. The positioning of the test specimens at the radius $(7.5 \mathrm{~cm}$ ) of the outer electrode (OE) will not

TABLE I

Summary: Dense Plasma Focus (DPF, LASL)

\begin{tabular}{|c|c|c|}
\hline & $\begin{array}{l}\text { Currant } \\
\text { Operatins } \\
\text { Pereeter. }\end{array}$ & $\begin{array}{l}\text { seoping" } \\
\text { Potentiol } \\
\text { gareeseters }\end{array}$ \\
\hline CL:dE:Sor Bank Enorgy, kJ & 420 & 2000 \\
\hline Z:Sedze, iks & -46 & -60 \\
\hline Dear :-istear, $M$ & 4.3 & $\sim 5$ \\
\hline I:=A :f Peak Curront, wee & $2-3$ & $2-3$ \\
\hline CAs & $(0, D)$ & $(0, I)$ \\
\hline Zas Etessure, Torr & $15-22$ & $15-22$ \\
\hline E:t:s::te tength, cm & 52 & 52 \\
\hline E-:t: Elactrode OE-Diasecer, sm & 13 & 15 \\
\hline i-.-.t: Eleztrode IE-Dianeter, cm & :o & 10 \\
\hline Set:s: Polse Wideh, nsec & 100 & 100 \\
\hline Se_tetr Yiela, bojpulse & $1.2 \times 10^{12}$ & $1 \times 10^{15^{6}}$ to $2.2 \times 10^{15^{d}}$ \\
\hline At:t:::isn Rate, pps & & 5 \\
\hline SE-T: incensity, n/wec & & $5 \times 10^{15} \mathrm{cos} 1.1 \times 10^{16}$ \\
\hline 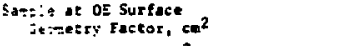 & & 700 \\
\hline 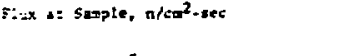 & • & $\begin{array}{c}7 \times 10^{12} \text { to } 1.5 \times 10^{13} \\
\left(2 \times 10^{13^{8}}\right)\left(4.5 \times 10^{13^{*}}\right)\end{array}$ \\
\hline i-jest: z: llty, E Number of Experiencs & & 8 \\
\hline 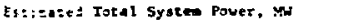 & & 10 \\
\hline
\end{tabular}

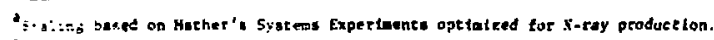

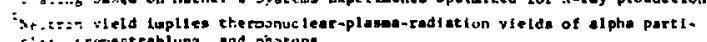

c:t9. - ressotrahluns, and phatuns.

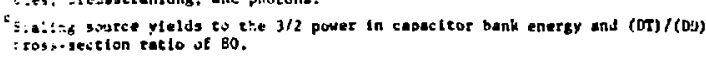

cas:t:s source yields as in $c$ phove except to the squase in copocitor benk

'poten:te! uceling fectol of 3 for Hother', Systens optinlzed for neutron s:zection.

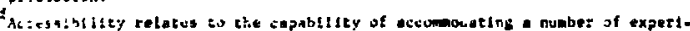
atits at the opecteles prein flux simuteaneoukly. perturb the formation of the focus. The geometry factcr of $700 \mathrm{~cm}^{2}$ would then make available a flux intensity of $7 \times 10^{12}$ to $1.5 \times 10^{13} \mathrm{n} / \mathrm{cm}^{2}-\mathrm{sec}$ depending on the scaling with the capacitor-bank energy.

\section{Accessibility. At the die-} tance of the $O E$, large-size test samples can be accommodated $(1-2 \mathrm{~cm}$ width, segmented or nonsegmented annular strips at the plane of the focus). The capability for large-size testing at the flux levels indicated introduces the possibility of meeting the needs of not only the surface program but also a broader scope of experiments in the bulk radiation program. An accessibility merit figure of eight is based on locating test specimens at the four cardinal and four intermediate radial positions.

\section{Options for the Radiation} Facility. The scaling by capacitorbank energy would have to depend on the experience gained in operating at 
lower bank energies. It may develop that the focus is found to be currelit limited, voltage limited, or both, in which case the upgrading of the facility would be through the pulsing rate. If these limits are not otserved in the range of the above operating levels, then the facility has the potantial of meeting the longerterm requircments of both the surface and bulk radiation programs. There are many options and combinations of options: scaling in capacitor-bank energy, scaling in pulsing rate, and improved geometry factors, that should be explored in a more detailed facility design study, and an expanded experimentation with large-scale plasma focus devices.

\section{REMARKS ON FACILITY DESIGN}

The cverall design study of the facility should include the following general areas :

a) plasma focus physics and plasma diagnostics for studying and confirming neutron scaling laws, and reproducibility;

b) engineering layout to optimize the accessibility of the neutron and

plasma source to a diverse and simultaneously executed experimental program;

c) energy storage and transfer systems in the range of several MJ;

d) repetition rate of energy storage and transfer systems in the range of several pps;

e) engineering heat-dissipation system for electrodes and energy storage;

f) mechanical design of the plasma device and total syctems components under cyclic mechanical stresses;

g) central electrode design and materials program for extending lifetime of electrode (surface erosion and minimize impurities into plasma);

h) engineering the tritium and deuterium fueling and recovery system,

vacuum and pumping systems;

i) engineering safeguards for tritium environment;

j) engineering the total remote handling of components for assembly and disassembly of subsystems, and for experimental components;

k) surface and materials study and assessment of pulsed versus continuous radiation effects; and

1) capital costs and operating costs per experiment.

\section{References}

[1] B. Coppi, H. P. Furth, M. N. Rosenbluth, R. Z. Sagdeev, Phys. Rev. Lett. 17, 377 (1966).

[2] D. F. Düichs, H. P. Furth, P. H. Rutherford, Proc. 6th European Conf. on Controlled Fusion and Plasma Physics, Moscow, July 30-Aug. 4, 1973. Joint

Institute for Nuclear Research, Moscow, Vol. I, p. 29.

[3] E. P. Gorbunov, V. S. Zaverjaev, M. P. Petrox, ibid, P. 1.

[4] F. DeMarco, Bill. Am. Phys. Soc. 18, 1253 (1973).

[5] S. Von Goele:, W. Stodiek, N. Sauthoff, ibid, p. 1254.

[6] E. Meservey, N. Bretz, D. Dimock, E. Hinnov, ibid, p. 1254.

[7] B. Coppi, Thys. Rev. Lett. 31, 1443 (1973).

[8] T. Kammash and D. L. Galbraith, Proc. 1st Topiezl Mtg. on Technology of Controlled Nuclear Fusion, San Diego, Calif., Apr. 17-18, 1974. ANS, p. 120.

[9] M. Kaminsky and S. K. Das, Proc. Conf. Surface Ef.fects in Controlled Thermonuclear Fusion Devices and Reactors, Argonne, I11., Jan. 10-12, 1974. North Holland Publishing Co., Amsterdam, p. 162.

[10] S. K. Des and M. Kaminsky, ibid, P. 115 .

[j.1] P. H. Rebul et al., ibid, p. 16.

[j.2] J. W. Mather: "Methods of Experimental Physics," 9, Part B, p. 187, Academic Press, New York (197!).

[13] C. Meisonnier, F. Pecorella, J. P. Rager, M. Samuelli, Proc. 5th European Conf. Controtled Fusion and Plasma Physics, Grenoble, Aug. 21-25, 1972.

Assoc. Euratom CEA, Paris, Vol. II, p. 183.

[14] A. Bernard et al., Proc. 2nd Topical Conf. Pulsed High-Beta Plasmas, Max-Planck Inst. für Plaswaphysik, Garching, July 3-6, 1972, p. E-1.

[15] P. D. Morgan et al., Proc. 6th European Conf. Controlled Fusion and Plasma Physics, Moscow, July 30-Aug. 4, 1073, Vol. I, p. 359.

[16] V. S. Imshennik, N. V. Fillippov, T. I. Filippova, Nuc1. Fusion 13, 929 (1973).

[17] L. Miche1, K. H. Schönbach, H. Fischer, App1. Phys. Lett. 24(2), 57 (1974).

$[18] \mathrm{K}$. Ware and J. Mather, LASL, private communication. 